\title{
Implementation of early management of iron deficiency in pregnancy during the SARS-CoV-2 pandemic
}

\author{
Tessa Stewart ${ }^{1}$, Joanna Lambourne ${ }^{2}$, Daryl Thorp-Jones ${ }^{1}$, and Wayne Thomas $^{1}$ \\ ${ }^{1}$ University Hospitals Plymouth NHS Trust \\ ${ }^{2}$ William Harvey Hospital
}

October 14, 2020

Title: Implementation of early management of iron deficiency in pregnancy during the SARS-CoV-2 pandemic

Stewart $\mathrm{T}^{1}$, Lambourne $\mathrm{J}^{2}$, Thorpe-Jones $\mathrm{D}^{1}$, Thomas $\mathrm{DW}^{1} .{ }^{1}$ University Hospitals Plymouth NHS Trust, Plymouth, Devon, PL6 8DH. ${ }^{2}$ East Kent Hospitals NHS Foundation Trust, William Harvey Hospital, Kennington Road, Willesborough, Ashford, Kent, TN24 0LZ

Main body of text:

This study assessed the prevalence of anaemia in a mixed metropolitan and urban setting in in the UK during first trimester of pregnancy to draw conclusions around managing iron deficiency.

The provision of healthcare has to adapt to new and innovative ways of delivering evidence-based good care in view of the SARS-CoV-2 pandemic. One area where this could be realised is in the management of iron deficiency particularly in pregnancy. There are excellent UK-based guidelines which need not be replaced but rather adapted in the light of current pandemic ${ }^{1}$.

Iron deficiency is common, particularly in women of child bearing age predominantly around menstrual blood loss and poor oral intake of iron-rich foods ${ }^{2}$. This issue becomes more pronounced during pregnancy with historically around a quarter of UK pregnancies associated with anaemia ${ }^{3}$. Whilst there is an international definition of anaemia during pregnancy, it is acknowledged that further work is required to validate them ${ }^{1}$.

Worldwide the commonest cause of anaemia is iron deficiency. The pathognomonic hallmark is a low serum ferritin, usually $<15 \mathrm{mcg} / \mathrm{l}$. In addition a serum ferritin of $<30 \mathrm{mcg} / \mathrm{l}$ indicates low iron stores ${ }^{4}$. Given that around $800 \mathrm{mg}$ of body iron is required for foetal development women either iron deficient and anaemic, iron deficiency without anaemia, or low iron stores without anaemia will to a decreasing extent risk running out of iron stores and becoming more anaemic during pregnancy. Even those with normal Hb and iron stores risk iron deficiency later in pregnancy.

Whilst post diagnosis treatment with oral iron still remains appropriate there is an ongoing possibility that such women may need intravenous iron or blood transfusion around delivery. In light of the SARS-CoV-2 pandemic this should be avoided if at all possible since it involves therapy within a healthcare setting. Under the current pandemic circumstances a more proactive approach is required.

We studied 1715 pregnancies during the 5 months of November and December 2018, March, April and May 2019. We looked at Haemoglobin ( $\mathrm{Hb}$ ) estimation at those booking prior to 13 weeks gestation. Our population has a very low carriage of haemoglobinopathy.

All full blood counts and serum ferritin assays were assessed on an Abbott Alinity hq and Architect analysers respectively. 
148 (8.6\%) women had $\mathrm{Hb}$ concentrations below $120 \mathrm{~g} / \mathrm{l}$ with 25 (1.5\%) below 110g/l. Median Hb was 132g/l; minimum $90 \mathrm{~g} / \mathrm{l}$, maximum of $160 \mathrm{~g} / \mathrm{l}$. The $95 \%$ lower limit confidence level was $116 \mathrm{~g} / \mathrm{l}$.

Guidance suggests that $\mathrm{Hb}$ values $>110 \mathrm{~g} / \mathrm{l}$ are adequate in the first trimester ${ }^{1}$. Our data shows the lower limit of normal in our cohort was $116 \mathrm{~g} / \mathrm{l}$. Hypothesising that the first trimester is not physiologically dissimilar to a pre-pregnant state we chose $\mathrm{Hb}<120 \mathrm{~g} / \mathrm{l}$ as our defining threshold for anaemia. Similar challenges of the definition of peri-operative anaemia in pregnant women also suggest targeting a higher Hb may be more appropriate $^{5}$.

We further assessed the outcome in pregnancies in November, December and March in those pregnancies where the booking $\mathrm{Hb}$ at less than 13 weeks gestation was below $120 \mathrm{~g} / \mathrm{l}$. Ninety of 1001 women during these months had $\mathrm{Hb}<120 \mathrm{~g} / \mathrm{l}$ giving a $9 \%$ incidence of anaemia by our definition. Of 81 evaluable cases $\mathrm{Hb}$ fell from booking to 28 week gestation by a median of $8 \mathrm{~g} / \mathrm{l}$ (range +39 to $-27 \mathrm{~g} / \mathrm{l}$ ) with 33 (41\%) dropping by $10 \mathrm{~g} / \mathrm{l}$ or more. No data on iron supplementation was collected.

Of the women with $\mathrm{Hb}<120 \mathrm{~g} / \mathrm{l}$ the average $\mathrm{MCV}$ and $\mathrm{MCH}$ were $87.5 \mathrm{fl}$ and $29 \mathrm{pg}$ respectively. Of these $17 \%$ had an MCV <80fl, and $27 \%$ had an $\mathrm{MCH}<28 \mathrm{pg}$. Most therefore had normal red cell indices.

In the 3 months assessed only 16 women (18\%) had their serum ferritin (SF) checked with a median value of $6.5 \mathrm{mcg} / \mathrm{l}$ (range 3 to 45 ). Thirteen of 16 women had SF below 30mcg/l. Although only a few cases, we saw an average fall in $\mathrm{Hb}$ of $3.5 \mathrm{~g} / \mathrm{l}$ (median rise of $2 \mathrm{~g} / \mathrm{l}$, range $-22 \mathrm{~g} / \mathrm{l}$ to $+15 \mathrm{~g} / \mathrm{l}$ ). One assumes that in those pregnancies found to have a low serum ferritin, iron supplementation was given. Of note the serum ferritin was only requested at booking if the $\mathrm{MCH}$ was found to be $<27 \mathrm{pg}$ (in all but one patient who had a normal $\mathrm{MCH})$ as part of the United Kingdom National Sickle cell and Thalassaemia screening programme.

Only 4 pregnancies were associated with blood transfusions.

Whilst we cannot show that low $\mathrm{Hb}$ at booking predicts for a transfusion requirement we can show that the incidence of anaemia in our first trimester population is around $9 \%$. We suggest that $\mathrm{Hb}$ values below $120 \mathrm{~g} / \mathrm{l}$ in the first trimester are not physiologically acceptable. For our cohort there is a fall in $\mathrm{Hb}$ between booking and 28 weeks of $8 \mathrm{~g} / \mathrm{l}$ which would generally be the accepted norm. The fall is less in the small number of cases that were shown to have low SF and therefore likely treated.

In the light of the current SARS-CoV-2 pandemic our study suggests that for all women at booking with $\mathrm{Hb}$ less than $120 \mathrm{~g} / \mathrm{l}$ we should offer low dose iron supplementation even if they have a normal serum ferritin. If the serum ferritin is below $30 \mathrm{mcg} / \mathrm{l}$ irrespective of the $\mathrm{Hb}$ iron should also be offered. This means that at least $9 \%$ of women will be given iron therapy at booking on the basis of their $\mathrm{Hb}$ alone. Using a low $\mathrm{MCV}$ or MCH to decide if serum ferritin testing is required seems to be wholly inappropriate since both MCV and $\mathrm{MCH}$ are in the majority normal in pregnant women at booking even with iron deficiency.

What do we suggest?

1) Universal screening for iron deficiency in the first trimester and treating cases with oral iron. We suggest that all women at booking who have $\mathrm{Hb}<120 \mathrm{~g} / \mathrm{l}$ or have low iron stores (serum ferritin $<30 \mathrm{mcg} / \mathrm{l}$ ) at booking start low dose oral iron.

Rationale: Most anaemia in pregnancy is due to iron deficiency and there will always be more demand on iron stores as pregnancy progresses. Pairing the full blood count with a serum ferritin avoids the risk of iron supplementation in persons with potential iron overload indicated by a raised serum ferritin. Although tolerability and compliance are potential issues, using a low dose is potentially better tolerated ${ }^{6}$. Starting early improves the chances of having sufficient stores later in pregnancy and attempts to reduce the need for intravenous iron. Low dose oral iron is typically ferrous sulphate $200 \mathrm{mg}$ alternate daily.

2) Once started on oral iron there is no requirement to monitor the effect until repeat testing at 28 weeks occurs unless the booking $\mathrm{Hb}$ is less than $100 \mathrm{~g} / \mathrm{l}$

Rationale: Whilst this seems at variance with standard practice where one would look to always gauge 
response after 2-4 weeks, the intention is to limit contact with the healthcare system as much as possible. Concerns around not monitoring could be met by telephone contact about symptoms and compliance or performing a full blood count and reticulocyte count on those felt to be at greater risk such as when the booking $\mathrm{Hb}$ is less than $100 \mathrm{~g} / \mathrm{l}$.

3) Only women with persistent iron deficiency despite oral iron should be considered for intravenous iron. Iron deficiency at or beyond 34 weeks and $\mathrm{Hb}<70 \mathrm{~g} / \mathrm{l}$ would be a strong indication for intravenous iron regardless of prior oral iron intake ${ }^{1}$. It should be considered for similar cases with $\mathrm{Hb}<100 \mathrm{~g} / \mathrm{l}$ but alternatives should be considered if symptoms allow for those persons iron deficient with $\mathrm{Hb}>100 \mathrm{~g} / \mathrm{l}$.

Rationale: One major aim is to reduce the need for intravenous iron for only those where all other choices have been explored. Alternative iron preparations may be considered, but ultimately intravenous iron may be the only option. Initial iron therapy orally is appropriate but recourse to intravenous iron is advised if severely iron deficient anaemic $(\mathrm{Hb}<70 \mathrm{~g} / \mathrm{l})$ or there is insufficient time for oral iron to work or be compliant with.

Compliance statements:

1. We, the authors, Disclosure no conflict of interests. This includes: relevant financial, personal, political, intellectual or religious interests.

2. All authors contributed equally to the final manuscript. TS, JL, and DWT performed the data analysis. DWT, DT-J and JL formulated the study concept. All authors (TS, JL, DT-J and DWT agreed the final manuscript prior to submission.

3. Ethics approval was not required since the study was a retrospective analysis of data already collected and used for the purposes of the UK National Antenatal Haemoglobinopathy screening programme. No additional blood samples were required for the study.

4. The study was not funded.

References:

1) Sue Pavord, Jan Daru, Nita Prasannan, Susan Robinson, Simon Stanworth and Joanna Girling on behalf of the BSH Committee. UK guidelines on the management of iron deficiency in pregnancy. British Journal of Haematology, 2020, 188, 819-830

2) WHO Guideline 2016: DAILY IRON SUPPLEMENTATION IN ADULT WOMEN AND ADOLESCENT GIRLS

3) Barroso, F., Allard, S., Kahan, B.C., Barroso, F., Allard, S., Kahan, B.C., Connolly, C., Smethurst, H., Choo, L., Khan, K. \& Stanworth, S. (2011). Prevalence of maternal anaemia and its predictors: a multi-centre study. European Journal of Obstetrics \& Gynecology and Reproductive Biology, 159, 99-105.

4) N. R. VAN DEN BROEK,1 E. A. LETSKY,2 S. A. WHITE, A. SHENKIN. Iron status in pregnant women: which measurements are valid? British Journal of Haematology, 1998, 103, 817-824

5) Furguson M.T, Dennis A.T. Defining peri-operative anaemia in pregnant women -challenging the status quo. Anaesthesia 2019, 74:237-45.

6) Diego Moretti, Jeroen S. Goede, Christophe Zeder, Markus Jiskra, Vaiya Chatzinakou, Harold Tjalsma, Alida Melse-Boonstra, Gary Brittenham, Dorine W. Swinkels, and Michael B. Zimmermann. Oral iron supplements increase hepcidin and decrease iron absorption from daily or twice-daily doses in iron-depleted young women. Blood. 2015;126(17):1981-1989) 